Journal of Sustainable Development of Transport and Logistics

journal home page: https://jsdtl.sciview.net

Prokudin, G., Oliskevych, M., Chupaylenko, O., \& Maidanik, K. (2020). Optimization model of freight transportation on the routes of international transport corridors. Journal of

Sustainable Development of Transport and Logistics, 5(1), 66-76. doi:10.14254/jsdtl.2020.51.7.

\title{
Optimization model of freight transportation on the routes of international transport corridors
}

\section{Georgiy Prokudin *(D), Myroslav Oliskevych $* *(\mathbb{D}$, , Olexiy Chupaylenko $* * *(\mathbb{D}$, Kateryna Maidanik $* * * *$ i}

${ }^{*}$ Department of International Transportation and Customs Control, National Transport University,

1, Mykhaila Omelianovycha - Pavlenka Str., Kyiv 01010, Ukraine

p_g_s@ukr.net

${ }^{* *}$ Department of International Transportation and Customs Control, National Transport University,

1, Mykhaila Omelianovycha - Pavlenka Str., Kyiv 01010, Ukraine

myroslav@3g.ua

*** Department of International Transportation and Customs Control, National Transport University,

1, Mykhaila Omelianovycha - Pavlenka Str., Kyiv 01010, Ukraine

dozentalexey@gmail.com

**** Department of International Transportation and Customs Control, National Transport University,

1, Mykhaila Omelianovycha - Pavlenka Str., Kyiv 01010, Ukraine

emaidanik@ukr.net

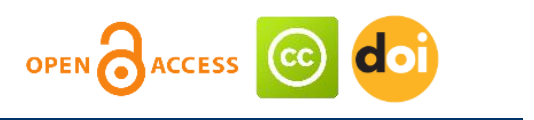

Article history:

Received: January 12, 2020

1st Revision: February 10, 2020

Accepted: April 08, 2020

DOI:

10.14254/jsdtl.2020.5-1.7
Abstract: The article deals with the modified Dijkstra's algorithm of searching the shortest routes between all transport nodes of the road-transport network, which allows presenting the transport problem in the classical matrix form. This makes it possible to apply each of the known methods of optimal transport plans to solve it. The object of study is the transport process of freight transportation on the transport network by routes of international transport corridors. The purpose of the work is to improve the methods of solving the problems of finding the shortest routes on the transport network, including sections of international transport corridors. The research method is the analysis and modeling of freight transportation on road networks. The modified Dijkstra's algorithm of finding the shortest paths between all nodes of the road-transport network was work out, which allows to represent the transport problem in the classical matrix form, i.e. in the form of a table of connections. This makes it possible to apply each of the known methods of constructing optimal plans of cargo transportation in the table of connections. The software complex based on the developed algorithm was designed in the algorithmic language Delphi, which was tested on the example of a transport problem set in the form of a road network, as well as complex testing and debugging of a computer system to support decision-making on the optimization of freight traffic on Ukrainian and Western Europe transport systems.

Corresponding author: Olexiy Chupaylenko

E-mail: dozentalexey@gmail.com

This open access article is distributed under a Creative Commons Attribution (CC-BY) 4.0 license. 
Keywords: Dijkstra's algorithm, shortest routes, freight transportation, road network, computer system.

\section{Introduction}

The strategic task of the scientific and technical policy in the field of the state transport industry is it's reaching the world level in terms of technical parameters and services quality provided by transport. In this regard, the urgent priority in this direction is to expand scientific research on the problems of creation of advanced technologies for the rational organization of freight transportation, the formation and functioning of an efficient transport system, the development of innovative control systems using modern information technologies.

The development of an efficient organization of cargo delivery consistency with all parts of the transport process caused a great deal of theoretical and experimental research on various issues of the development of transport systems.

The relevance of research is determined by the need to increase the efficiency of cargo transportation in international traffic by developing and implementing models, methods and software for the process of rational organization of international cargo transportation routes of international transport corridors.

The geographical position of Ukraine determines its importance for the European Transport System in determining the optimal ways of transportation of goods and passengers. Shortest routes from Western Europe to the Caucasus, Central Asia, Iran, and Afghanistan; from Central and Northern Europe to the ports of the Black Sea, the Middle East countries pass through the territory of Ukraine. Ukraine has an extensive network of highways (total length of highways in Ukraine is 172.4 thousand $\mathrm{km}$ ), one of the most powerful in Europe railway network (length of railways in Ukraine is 22.3 thousand km), which organically connects with Europe through Poland, Slovakia, Hungary, Romania, Moldova, Bulgaria and cover the sea and river ports of the Black Sea - Azov basin (Prokudin, 2006, p.156).

The concept "Creation and functioning of the national network of international transport corridors in Ukraine" (Resolution No. 821 of the Cabinet of Ministers of 04.08.1997) was developed on the basis of the principles of international transport policy adopted in European co-authorship, which include: political aspects, social progress, commercial aspects, tariff policy, organization of transportations, development of infrastructure and service, crossing of state borders, technical and technological problems caused by liberalization and harmonization of transport about the market, environmental requirements and job security and more.

Integration of Ukraine into the international transport system involves adherence to existing transport corridors and new areas of MTK, namely:

- continuation of corridors No. 3 and the direction Europe - Asia is Frankfurt - Krakow - Kyiv Almaty;

- continuation of the corridor No. 5: Lviv - Rivne - Cernay - Minsk;

- continuation of the Baltic-Black sea: Gdansk - Warsaw - Kovel - Odesa;

- continuation of the direction North-South: Kharkiv - Poltava - Kirovograd - Odesa; Ashgabat;

- extension of the Eurasian transport corridor (UTC): Odesa - Tbilisi (Yerevan) - Baku -

- the continuation of the project black sea economic cooperation (BSEC) in Ankara - Yerevan Tbilisi (Baku) - Rostov-on-don - Donetsk - Odesa (Chisinau) - Bucharest (Tirana) - Dimitrovgrad (Athens) - Istanbul.

Increasing the role of freight transport service international cargo, strengthening the role of forwarding activities in the formation of supply and demand has fundamentally changed the concept of the transport market. On the other hand, the creation of a single international transport and logistics system and the geographical position of the transport space as MTK requires separate analysis of work management of transport hubs coordination and interaction of transport, impact of scientific and technological progress on transport. The process of the formation of the international transportation system is not complete. Moreover, the final solution of several problems of transport 
and the development of new technologies will be realized only at the turn of the first quarter of the XXI century.

\section{Review of publications}

Many scientific works in the field of transport systems, logistics and operations research are devoted to solving the problems of increasing the efficiency of internationally cargo transportation. The main characteristics of road networks include: maximum flow on the network and the shortest distances on the network (Aulin et al., 2019; 2020; Prokudin, 2006, p.156). To solve the problem of optimization of the transport network, it is necessary to be able to reduce the network representation of the transport problem to a matrix form for which there is a practical mathematical apparatus of transportation optimization (Prokudin, 2018, p.16).

Existing solving methods of maximum flow on a transport network problem are convenient to use for the flat network only (Lashenykh, 2006, p.203). The above algorithm for "maximum flow" allows optimizing the solution of the problem, but does not take into account the features of transport networks (Teodorovic, 2016, p. 31). One needs to extend the method to solve the problem with optimization of transport networks with and without network bandwidth restrictions.

In the process of functioning of different components of transport systems, there is a constant need to solve problems related to their work as queuing systems of different types of requirements. This is due to the fact that their purpose, as a rule, is to serve various consumers of transport services (orders). Therefore, solving the problems of analysis and optimization of modes of operation of different links of transport systems is quite relevant and is able to significantly improve the efficiency of transport use in various sectors of the economy (Cormen, 2006, p.656).

The operation of individual components of transport systems (TS) is considered in this case as a set of sequentially connected inbound flows of service requirements (vehicles, passengers, etc.), service channels (checkpoints, service stations, etc.) and outbound flows of requirements after service (Knight, 2014, p.24).

The variety of applications of queuing theory determines the growing interest in it, and the complexity of emerging problems does not allow to obtain comprehensive solutions based on analytical methods, even with the numerical implementation of the latter (Cancela, 2015, p.21). In such situations, it is compulsory to use simulation modeling, which is an indispensable tool for analyzing the operational and many other characteristics and parameters of the systems under study. A promising area of research is the use of modern computer information technology in simulation modeling in relation to transportation queuing systems (Pu, 2016, p.263).

Implementations of the process of queuing system operation (QSO) are modeled on a computer using a series of random or pseudorandom quantities. The averaging of the simulation results by the time of model operation or by the number of process realizations allows the mathematical statistics methods to obtain the desired system characteristics.

A QSO simulation model is a model that shows how the system behaves and how its state will change over time with the specified flow of requirements coming to the system inputs. Requirements Input Flow Parameters are external QSO parameters. The initial parameters are values that characterize the properties of the system and the quality of its functioning. Simulation modeling allows you to investigate QMS with different types of input streams and different intensities of system requirements, as well as different discipline of service requirements (Singh, 2016, p.163).

Today, in the software world, GPSSW (General Purpose Simulation System World) is the most powerful and versatile simulation environment for professional modeling of a wide variety of processes and systems (Wu, 2014, p.55). This system is intended for modeling of discrete, mainly QMS and continuous systems. It is a very effective simulation tool, independent of the limitations of analytical and numerical methods, sufficiently "transparent", which allows for non-standard data processing and eliminates many non-trivial problems of programming and debugging models (Zou, 2016, p.53). 


\section{Research methods}

The current state of the economy of the advanced countries of the world is currently not possible without a correspondingly high level of development of their transport systems, intended, first of all, to meet the needs of the national economy of these countries, in the economic transportation of passengers and cargo. In addition, there is a tendency of the world economy for transnational penetration and integration (Kavita, 2014, p.222), which puts additional demands on the transport system (TS) for sharing different modes of transport and, as a consequence, increasing the efficiency of transportation different cargoes using international transport corridors. Let's try to present the transport process of all modes of transport that are included in international transport corridors, namely - road, rail and water, which includes sea and river in the form of a generalized model of multimodal freight transportation (Semenov, 2004, p.41).

The presentation of multimodal freight transport in the form of a mathematical model allows us to analyze the use of different modes of transport. Suppose we have a number of transport nodes (TN) connected by appropriate transport communications (for vehicles of Ukraine and Western Europe the number of TN is 794)( Lashenyh, 2016, 42). A necessary condition for a TN membership in this set is the presence of roads connecting it to a common transportation system. And in TN can be located either railway stations $(\mathrm{r} / \mathrm{s})$, or water ports $(\mathrm{w} / \mathrm{p})$ or their various combinations, which can be represented graphically in the form of the following 4 types: - TN without $\mathrm{r} / \mathrm{s}, \mathrm{w} / \mathrm{p}$ - 1 type (set M1 includes 156 TVs);

- TN in which the r / s - 2 type is located (the set M2 includes 520 TVs);

- TN, in which the w/ p- - 3 type is located (the set M3 includes 75 TVs);

- TN, in which are located with $\mathrm{r} / \mathrm{s}$ and $\mathrm{w} / \mathrm{p}$ - 4 type (set M4 includes $43 \mathrm{TV}$ );

and we have the following relation:

$$
M \in \bigcup M_{i}, \quad i=\overline{1,4},
$$

where $\mathrm{M}$ is the set of all TN.

It should also be noted that multimodal transport of goods between TN can be carried out either using one or more modes of transport. And in the latter case, the most often combined transportation by road and some other mode of transport to implement the technology "door to door".

The following methods were used in order to achieve this goal: improvement of the methods for solving the maximum flow problems and the methods of finding the shortest distances on the transport network.

\section{Research results}

Mathematical programming algorithms for transport network design have been developed that allow finding optimal routes. But these algorithms do not take into account the large number of intermediate points in the transport network. The proposed transport characteristics in the multiplex system are suitable for optimization but do not allow calculating the shortest paths in the case of a large number of intermediate points (Zakharov, 2014, p.49).

The transport problem is represented equally in matrix and network forms by purpose. However, sometimes it is more convenient to solve a network problem in matrix form. But these methods need to be improved in order to solve complex network transport problems using oriented graphs (Bekmagambetov, 2012, p.28).

Overall, the problem of effective control of the process of international freight transportation is that the existing methods do not fully take into account the specific features of their implementation and, as a consequence, no unified approach to defining methods was developed.

The object of research of this article is the process of international freight transportation in transport systems on routes of international transport corridors (Srour, 2016, p.42).

Let's consider the transport system (TS) of Ukraine and Western Europe, which includes 602 transport nodes, settlements (S), which are connected by appropriate transport communications. A necessary condition for belonging of $S$ to this set is the presence of roads combining this $S$ in general 
TS. And railway stations (RS), water ports (WP) or their various combinations can be located in the S. Combined ports can be classified as follows:

- 88 - S without RS and WP - ( $M_{1}$ set);

- $389-\mathrm{S}$, which are provided only with RS - $\left(M_{2}\right.$ set);

- $91-\mathrm{S}$, which are provided only with WP - $\left(M_{3}\right.$ set);

- $34-\mathrm{S}$, which are provided both RS and WP - (M $M_{4}$ set),

and we have the following relation

$$
M \in M_{i}, \quad i=\overline{1,4}
$$

where $M$ is a set of all $\mathrm{S}$.

Based on the fact that transportation between settlements can be carried out either using one mode of transport or by several modes, we have the following options for transportation of goods (Prokudin, 2016, p.127):

1) transportation by road is carried out from the supplier of any type to the consumer of any type, i.e. according to the following scheme:

$S 1 \div 4$ of type $\rightarrow S 1 \div 4$ of type

and is equal to:

$$
K_{1}=2 ! \cdot C_{M}^{2}+\ldots+(M-1) ! \cdot C_{M}^{M-1} \text { transportation combinations; }
$$

Note: The sign $\rightarrow$ indicates the process of transportation;

2) transportation by rail assumes that a supplier and a consumer of cargo are provided with RS and is carried out according to the next scheme:

$S 2,4$ of type $\rightarrow S 2,4$ of type and is equal to: $K_{2}=2 ! C_{M_{2}+M_{4}}^{2}+3 ! C_{M_{2}+M_{4}}^{3}+\ldots+\left(M_{2}+M_{4}-1\right) ! C_{M_{2}+M_{4}}^{M_{2}+M_{4}-1}$ transportation combinations;

3) transportation by water means assuming the providing of a supplier and a consumer of goods WP and carried out according to the following scheme:

$S 3,4$ type $\rightarrow S 3,4$ type and is equal to:

$K_{3}=2 ! C_{M_{3}+M_{4}}^{2}+3 ! \cdot C_{M_{3}+M_{4}}^{3}+\ldots+\left(M_{3}+M_{4}-1\right) ! C_{M_{3}+M_{4}}^{M_{3}+M_{4}-1}$ transportation combinations;

4) transportation first by road and then by water means the movement of cargo first from the supplier of any type of motor transport to the closest to WP and then by water transport to the consumer of goods having the WP and are carried out according to the following scheme: $S \quad 1 \div 4$ type $\rightarrow S 3,4$ type $\rightarrow S 3,4$ type

and is equal to:

$$
K_{4}=K_{1} \cdot K_{3} \text { transportation combinations; }
$$

5) transportation by water first, and then by motor vehicles assume the movement of cargo first from the $S$ of the supplier having WP to the nearest to the $S$ of the consumer of the cargo WP and then by motor transport to the $\mathrm{S}$ of any type and are carried out according to the following scheme: $S 3,4$ type $\rightarrow S 3,4$ type $\rightarrow S 1 \div 4$ type

and is equal to:

$$
K_{5}=K_{3} \cdot K_{1} \text { transportation combinations; }
$$

6) transportation first by road, after water transport, and then again by road modes of transport assume the movement of cargo by road first from the supplier of any type to the nearest WP, after the water transport to the nearest consumer of cargo $S$, and then by vehicles to the goods consumer of any type, and are carried out according to the following scheme: $S 1 \div 4$ type $\rightarrow S 3,4$ type $\rightarrow S 3,4$ type $\rightarrow S 1 \div 4$ type

and is equal to:

$$
K_{6}=K_{1} \cdot K_{3} \cdot K_{1} \text { transportation combinations; }
$$

7) transportation, first by road and then by rail, involves the movement of cargo, first from the supplier of any type of vehicle to the nearest railway station and then by rail to the consumer of goods 
with RS and then by rail to the freight consumer provided by RS and carried out according to the following scheme: $S \quad 1 \div 4$ type $\rightarrow S \quad 2,4$ type $\rightarrow S 2,4$ type

and is equal to:

$$
K_{7}=K_{1} \cdot K_{2} \text { transportation combinations; }
$$

8) transportation by rail first, and then by vehicles, imply the movement of cargo first from $S$ of the supplier provided with RS with the railway transport to the nearest $S$ consumer of the cargo with $\mathrm{RS}$ and then by vehicles to the $S$ consumer of the cargo of any type and carried out according to the following scheme: $S \quad 2,4$ type $\rightarrow S \quad 2,4$ type $\rightarrow S \quad 1 \div 4$ type

and is equal to:

$$
K_{8}=K_{2} \cdot K_{1} \text { transportation combinations; }
$$

9) transportation first by road, after railway, and then again by road modes of transport, assume the movement of cargo by road first from the supplier of any type to the nearest to him RS, after the railway to the nearest cargo customer with RS and then to goods consumer by vehicle of any type, and are carried out according to the following scheme: $S \quad 1 \div 4$ type $\rightarrow S \quad 2,4$ type $\rightarrow S \quad 2,4$ type $\rightarrow S \quad 1 \div 4$ type and is equal to:

$$
K_{9}=K_{1} \cdot K_{2} \cdot K_{1} \text { transportation combinations. }
$$

Proceeding from the above the total number of freight combinations will be:

$$
K=\sum_{i=1}^{9} K_{i} \quad(i=\overline{1,9)}
$$

It should be noted that these transportations may be made necessarily by the shortest route through several intermediate (transit) S. The indicators of the quality of transportation are the time or cost of their completion. Note that the transport process at such initial formulation can be carried out in the following four ways (Prokudin, 2018, p.16):

I way - transportation is carried out by one type of transport $(1,2$ and 3 variants of transportation) directly from the supplier of cargo to its consumer;

II way - transportation is carried out first by vehicles from the transport node of the supplier of cargo to the nearest transport node having the appropriate transport node, and then to the consumer of that cargo by the appropriate mode of transport having the corresponding transport node ( 4 and 7 variants of transportation);

III way - transportation is carried out first by means of the appropriate mode of transport from the supplier of cargo to the nearest consumer of that cargo of the respective transport node, and then to the consumer by vehicle ( 5 and 8 variants of transportation);

IV way - transportation is carried out first by means of road transport from the supplier of cargo to the nearest transport node, then by the appropriate mode of transport to the transport node nearest to the consumer, and by road transport at the end of way ( 6 and 9 variants of transportation).

There are a couple of things to note about the transportation methods above:

- the shortest routes may be through S for all modes of transportation of goods, in which the same cargo is required;

- transportation of cargoes can be carried out through several intermediate $S$ for all modes which have stocks of these cargoes;

- several types of cargo can be transported simultaneously in all ways;

- additional restrictions of the transport process are the capacity of transport nodes and highways (Prokudin, 2016, p.132).

\section{Discussion}

Lets consider the model of optimization of freight transportation by routes of international transport corridors on a specific example of a transport network (TN), which includes seven S, which are interconnected by route communications with the distances indicated on them (Fig. 1). 
Figure 1: Transport network

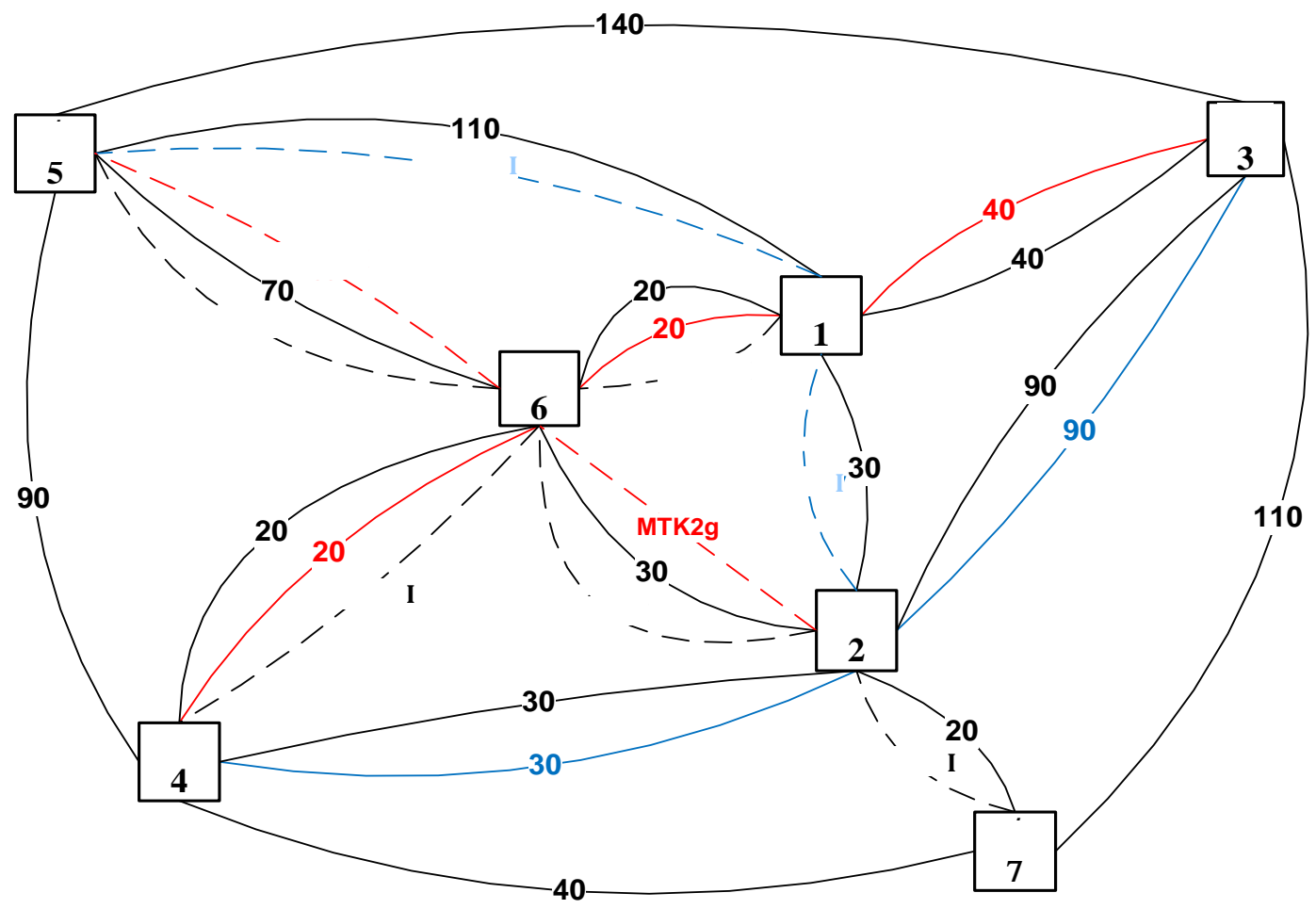

The routes of two conditional international transport corridors (ITC) - ITC1 and ITC2 are also presented in Figs.1. ITC1 is aqueous, as evidenced by the symbol $v$ in its name, and ITC2a is the road and ITCg rail sections of ITC2. To simplify the model the distances of the ITC sections were corresponded to the distances of the TN sections.

The database (DB) includes 8 files: G_d - an array of RS (6 RP), which is indispensable condition for their presence in the N_p array; Marsh_gd - array of sections of railways (5 sections); N_p - array of $\mathrm{S}$ lying on motorways (7 S) and Marsh_avto - array of sections of motorways (14 sections); $V_{-} p$ - an array of river and seaports (5 RP), which is also a prerequisite for their presence in the N_p array; Marsh_voda - array of sections of sections of waterways (4 sections); ITC1v is an ITC array of water sections (2 sections) that are added to the Marsh_voda array and ITC2a is ITC array of rail sections (2 sections) that are also added to the Marsh_gd array and an automotive section array (4 sections) that are included in the $\mathrm{N}_{-}$array

File N_p:

\begin{tabular}{lll}
\hline Kod & Naim & Kol_g \\
\hline 1 & S 1 & 5000 \\
2 & S 2 & 16500 \\
3 & S 3 & 9000 \\
4 & S 4 & 2800 \\
5 & S 5 & 34500 \\
6 & S 6 & 56700 \\
7 & S 7 & 990000 \\
\hline
\end{tabular}

File Marsh_avto:

\begin{tabular}{lllll}
\hline Kod & I_N & P_O & P_N & L \\
\hline 1 & M-1 & S 3 & S 1 & 50 \\
2 & M-1 & S 1 & S 6 & 20 \\
3 & M-1 & S 6 & S 4 & 20 \\
4 & M-1 & S 4 & S 5 & 90 \\
5 & E-1 & S 3 & S 2 & 90 \\
6 & E-1 & S 2 & S 6 & 30 \\
7 & E-1 & S 6 & S 5 & 70 \\
8 & P-1 & S 3 & S 5 & 140 \\
9 & P-2 & S 3 & S 7 & 110 \\
10 & G-1 & S 1 & S 5 & 110 \\
11 & G-2 & S 1 & S 2 & 30 \\
12 & G-3 & S 2 & S 7 & 20 \\
13 & G-4 & S 4 & S 7 & 40 \\
14 & G-5 & S 2 & S 4 & 30 \\
\hline
\end{tabular}


File G_d:

\begin{tabular}{lll}
\hline Kod & N P & Kolg \\
\hline 1 & S 1 & 5000 \\
2 & S 3 & 9000 \\
3 & S 4 & 2800 \\
4 & S 6 & 56700 \\
5 & S 5 & 34500 \\
6 & S 2 & 16500 \\
\hline
\end{tabular}

File V_p:

\begin{tabular}{lll}
\hline Kod & N_P & Klass \\
\hline 1 & S 2 & 2 \\
2 & S 3 & 2 \\
3 & S 4 & 2 \\
4 & S 1 & 1 \\
5 & S 5 & 1 \\
\hline
\end{tabular}

File MTK1:

\begin{tabular}{lllll}
\hline Kod & I_N & P_O & P_N & V \\
\hline 1 & M5-1 & S 5 & S 1 & 110 \\
2 & M1-2 & S 1 & S 2 & 30 \\
\hline
\end{tabular}

File Marsh_gd:

\begin{tabular}{lllll}
\hline Kod & I_N & P_O & P_N & L \\
\hline 1 & Z-1 & S 3 & S 1 & 40 \\
2 & Z-2 & S 1 & S 6 & 20 \\
3 & Z-3 & S 6 & S 4 & 20 \\
4 & Z-4 & S 5 & S 6 & 70 \\
5 & Z-5 & S 6 & S 2 & 30 \\
\hline
\end{tabular}

File Marsh_voda:

\begin{tabular}{lllll}
\hline Kod & I_N & P_O & P_N & L \\
\hline 1 & P-1 & S 3 & S 2 & 90 \\
2 & P-2 & S 2 & S 4 & 30 \\
3 & M-1 & S 5 & S 1 & 110 \\
4 & M-2 & S 1 & S 2 & 30 \\
\hline
\end{tabular}

File MTK2:

\begin{tabular}{llllll}
\hline Kod & I_N & P_O & P_N & A & G \\
\hline 1 & M5-6 & S 5 & S6 & 70 & 70 \\
2 & M6-2 & S 6 & S 2 & 30 & 30 \\
3 & M6-1 & S 6 & S 1 & 20 & \\
4 & M6-4 & S 6 & S 4 & 20 & \\
5 & M2-7 & S 2 & S 7 & 20 & \\
\hline
\end{tabular}

A matrix of direct links of all S of the analyzed TN will appear on the screen after launching the software-optimization complex of transportation optimization (SOCTO) on the transport system of Ukraine and Western Europe, and testing procedure of transformation of DB of transport modes in the matrix of transport correspondences (Prokudin, 2016, 56).

It should be noted that first, the matrix is symmetric due to the non-orientation of the $\mathrm{TN}$, and second, if the settlements do not have direct transport links then the distance between them is determined to be greater than each of the available distances on the TN.

Then the procedure of searching the optimal routes of freight transportation on the TN starts to find the most favorable (in our case in terms of cost of transportation) combinations of different modes of transport and to form an appropriate optimal route of freight transportation (Prokudin, 2018,52 ) Let's consider this procedure step by step, and first consider the array of records mas_min: Array (Prokudin, 2016, 57) of min_str, which has the record min_str of the following structure:

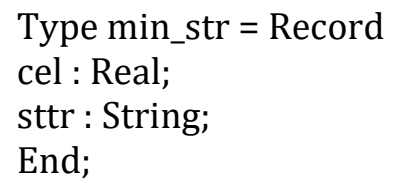

This set of records consisting of three elements by the number of modes of transport, during the operation of the SOCTO is filled with a minimum cost of transportation of 1 ton of cargo from the current point of supply to the point of consumption (field cel) and the corresponding value of the route of transport (field sttr):

$$
\begin{array}{cccc}
\text { mas_min[1].cel }:= & \text { voda; } & \text { mas_min[1].sttr }:= & \text { sttr_voda; } \\
\text { mas_min[2].cel }:= & \text { gd; } & \text { mas_min[2].sttr }:= & \text { sttr_gd; } \\
\text { mas_min[3].cel }:= & \text { avto; } & \text { mas_min[3].sttr }:= & \text { sttr_avto. }
\end{array}
$$

For our example, the contents of the mas_min array will be as follows:

for the supplier $\mathrm{S} 7$ and for the customer $\mathrm{S} 3$ :

mas_min[1].cel := 134.00; mas_min[1].sttr := 'by VEHICLE from S 7 to S 2 for the price $=44.00 \mathrm{UAH}$ by STEAMSHIP from $S 2$ to $S 3$ for the price $=90.00 \mathrm{UAH}^{\prime}$; 
mas_min[2].cel := 179.00; mas_min[2].sttr := "by VEHICLE from S 7 to $\mathrm{S} 2$ for the price $=44.00 \mathrm{UAH}$ by TRAIN from S 2 to S 6 for the price $=45.00 \mathrm{UAH}$ from S 6 to $\mathrm{S} 1$ for the price $=30.00 \mathrm{UAH}$ from S 1 to $\mathrm{S} 3$ for the price $=60.00 \mathrm{UAH}$;

mas_min[3].cel := 198.00; mas_min[3].sttr := "by VEHICLE from S 7 to $\mathrm{S} 2$ for the price $=44.00 \mathrm{UAH}$ from $\mathrm{S} 2$ to $\mathrm{S} 1$ for the price $=66.00 \mathrm{UAH}$ from S 1 to $\mathrm{S} 3$ for the price $=88.00 \mathrm{UAH}$ '.

for the supplier $\mathrm{S} 7$ and for the customer $\mathrm{S} 5$ :

mas_min[1].cel := 184.00; mas_min[1].sttr := 'by VEHICLE from S 7 to $S 2$ for the price $=44.00$ by STEAMSHIP from $S 2$ to $S 1$ for the price $=30.00 \mathrm{UAH}$ from $\mathrm{S} 1$ to $\mathrm{S} 5$ for the price $=110.00 \mathrm{UAH}$; mas_min[2].cel := 194; mas_min[2].sttr := 'by VEHICLE from S 7 to $\mathrm{S} 2$ for the price $=44.00 \mathrm{BY}$ TRAIN from S 2 to $S 6$ for the price $=45.00 \mathrm{UAH}$ from S 6 to $S 5$ for the price $=105.00 \mathrm{UAH}$;

mas_min[3].cel $:=\mathbf{2 6 4 . 0 0}$; mas_min[3].sttr := "by VEHICLE from S 7 to $S 2$ for the price $=44.00 \mathrm{UAH}$ from $S 2$ to $S 6$ for the price $=66.00 \mathrm{UAH}$ from $\mathrm{S} 6$ to $\mathrm{S} 5$ for the price $=154.00 \mathrm{UAH}^{\prime}$.

for the supplier $S 4$ and for the customer $S 3$ :

mas_min[1].cel $:=\underline{\mathbf{1 2 0 . 0 0}}$; mas_min[1].sttr := "by STEAMSHIP from S 4 to S 2 for the price $=30.00$ UAH from S 2 to $\mathrm{S} 3$ for the price $=90.00 \mathrm{UAH}^{\prime}$;

mas_min[2].cel $:=\mathbf{1 2 0 . 0 0}$; mas_min[2].sttr := "by TRAIN from S 4 to $\mathrm{S} 6$ for the price $=30.00 \mathrm{UAH}$ from S 6 to $\mathrm{S} 1$ for the price $=30.00 \mathrm{UAH}$ from S 1 to $\mathrm{S} 3$ for the price $=60.00 \mathrm{UAH}^{\prime}$;

mas_min[3].cel := 176.00; mas_min[3].sttr := "by VEHICLE from S 4 to $S 6$ for the price $=44.00 \mathrm{UAH}$ from $S 6$ to $\mathrm{S} 1$ for the price $=44.00 \mathrm{UAH}$ from $\mathrm{S} 1$ to $\mathrm{S} 3$ for the price $=88.00 \mathrm{UAH}^{\prime}$.

for the supplier $S 4$ and for the customer $S 5$ :

mas_min[1].cel := 170.00; mas_min[1].sttr := 'by STEAMSHIP from S 4 to $S 2$ for the price $=30.00$ UAH from $S 2$ to $S 1$ for the price $=30.00 \mathrm{UAH}$ from $\mathrm{S} 1$ to $S 5$ for the price $=110.00 \mathrm{UAH}^{\prime}$;

mas_min[2].cel $:=\underline{\mathbf{1 3 5 . 0 0}}$; mas_min[2].sttr := "by TRAIN from S 4 to $\mathrm{S} 6$ for the price $=30.00 \mathrm{UAH}$ from $S 6$ to $S 5$ for the price $=105.00 \mathrm{UAH}^{\prime}$;

mas_min[3].cel := 198.00; mas_min[3].sttr := "by VEHICLE from $S 4$ to $S 5$ for the price $=198.00$ UAH'.

A matrix of the cheapest routes is formed for each pair of suppliers and consumers of cargo as a result of this procedure applying. The method of optimization of transportation (its the differential rent method in this case) is then applied to the resulting matrix, which together with the specified volumes of deliveries and orders of cargo is nothing like the transportation table. We have got the optimum plan of cargo transportation on the given TN finally.

The results of formulated in our example network transport problem (NTP) solving are:

- routes of transportation of cargo from each supplier to each consumer, specifying the types of transport, volumes of transportation and the cost of transportation of the unit of cargo on each route;

- the minimum cost of implementation of the transportation plan;

- the total time of implementation of the transportation plan;

- the time of completion of the transportation plan;

- the total volume of cargo carried.

For a example, the first route of cargo transportation partially (32.84\%) passes through the motor component of ITC2, namely a VEHICLE from the S7 to S2 for $20 \mathrm{~km}$, and also the third route of cargo transportation partially (77.78\%) passes through the railway component of ITC2, namely by TRAIN from S6 to S5 for $70 \mathrm{~km}$. The overall percentage of the use of ITC routes in transportation of cargo according to the optimal plan after the cost criterion is $58.10 \%$.

\section{Conclusions}

The description of the model of complex transportation in the TS makes it possible to system approach to the task of optimizing the transportation of goods by a combined scheme of use of different types of transport (road, water and rail) from a practical point of view, taking into account the whole spectrum of restrictions existing in such systems. The description of the structure and content of the DB of different modes of transport represents in general the infrastructure of the transport system of Ukraine and Western Europe, which converts the corresponding DB into a matrix of transport correspondences by means of a special procedure. The matrix representation of the 
transport process, in turn allows to describe it in the form of an appropriate mathematical model and to apply the methods and means of modern information technologies in its analysis. The procedure of finding the optimal freight plans on TN allows one to choose the cheapest variant of cargo transportation from all existing for two modes of optimization of cargo transportation, either on the criterion of cost or on the criterion of time. The use of international transport corridor routes in the process of finding the optimal freight plan helps to greatly improve the quality of the decisions made.

\section{Citation information}

Prokudin, G., Oliskevych, M., Chupaylenko, O., \& Maidanik, K. (2020). Optimization model of freight transportation on the routes of international transport corridors. Journal of Sustainable Development of Transport and Logistics, 5(1), 66-76. doi:10.14254/jsdtl.2020.5-1.7.

\section{References}

Aulin, V., Hrynkiv, A., Lyashuk, O., Vovk, Y., Lysenko, S., Holub, D., ... \& Lavrentieva, 0. (2020). Increasing the Functioning Efficiency of the Working Warehouse of the "UVK Ukraine" Company Transport and Logistics Center. Communications-Scientific letters of the University of Zilina, 22(2), 3-14. https://doi.org/10.26552/com.C.2020.2.3-14

Aulin, V., Lyashuk, O., Pavlenko, O., Velykodnyi, D., Hrynkiv, A., Lysenko, S., Holub, D., Vovk, Y., Dzyura, V., \& Sokol, M. (2019). Realization of the Logistic Approach in the International Cargo Delivery System. Communications - Scientific Letters of the University of Zilina, 21(2), 3-12. Retrieved from http://komunikacie.uniza.sk/index.php/communications/article/view/1462

Bekmagambetov, M., \& Kochetkov, A. (2012). Analysis of modern software of transport simulation of research, design, technology. Journal of Automotive Engineers, 6(77), 25-34. Retrieved from http://www.aae-press.ru/f/77/25.pdf.

Cancela, H., Mauttone, A., \& Urquhart, M. E. (2015). Mathematical programming formulations for transit network design. Transportation Research Part B: Methodological, 77, 17-37. doi:10.1016/j.trb.2015.03.006.

Cormen, T., Rivest, C., \& Stein, R. (2006). Section 26.2: The Ford-Fulkerson method. Introduction to Algorithms (Second ed.). MIT Press and McGraw-Hill.

Kavita G. (2014). An algorithm for solving a capacitated indefinite quadratic transportation problem with enhanced flow. Yugoslav Journal of Operations Research, 24, 217-236. doi:10.2298/yjor120823043g.

Knight, H. (2014). New algorithm can dramatically streamline solutions to the 'max flow' problem. MIT News, 4, 21-26.

Lashenyh, A., \& Turpak, S. (2016). Development of mathematical models for planning the duration of shunting operations. Eastern-European Journal of Enterprise Technologies, 5/3(83), 40-46. doi:10.15587/1729-4061.2016.80752.

Prokudin, G. (2006). Modeli i metody optimizatsii perevezen' u transportnykh systemakh [Models and methods of optimization of transportation in transport systems]. Kyiv: NTU Publ [in Ukrainian].

Prokudin, G., Chupaylenko, A., \& Dudnik, A. (2016). The conversion process network models of freight transport in the matrix model. Project Management, Systems Analysis and Logistics. Science Journal, 16(1), 125-136.

Prokudin, G., Chupaylenko, O., \& Dudnik, O. (2016). Improvement of the methods for determining optimal characteristics of transportation networks. Eastern-European Journal of Enterprise Technologies, 6/3 (84), 54-61. https://doi.org/10.15587/1729-4061.2016.85211

Prokudin, G., Chupaylenko, O., \& Dudnik, O. (2018). Application of information technologies for the optimization of itinerary when delivering cargo by automobile transport. Eastern-European Journal of Enterprise Technologies, 2/3 (92), 51-59. doi:10.15587/1729-4061.2018.128907.

Prokudin, G., Chupaylenko, O., \& Dudnik, O. (2018). Optimization of transport processes with the use of information technologies. European Journal of Intelligent Transportation Systems, 1(1), 11. doi:10.31435/rsglobal_ejits.

$\mathrm{Pu}, \mathrm{C} ., \mathrm{Li}, \mathrm{S} .$, Yang, Y., \& Wang, K. (2016). Information transport in multiplex networks. Statistical Mechanics and its Applications, 477, 261-269. doi:10.1016/j.physa.2015.12.057. 
Semenov, V. (2004). Mathematical modeling of dynamics of transport flows of a metropolis. Preprints of the IPM M. V. Keldysh, 034, 38-45. Retrieved from http://spkurdyumov.ru/uploads/2013/08/Semenov.pdf.

Singh, S., Dubey, G. C., \& Shrivastava, R. (2016). Various method to solve the optimality for the transportation problem. Statistical Mechanics and its Applications, 12, 161-169.

Srour, F. J., \& Newton, D. (2006). Freight-specific data derived from intelligent transportation systems: Potential uses in planning freight improvement projects. Transportation Research Record, 1957(1), 66-74. doi:10.3141/1957-10.66-74.

State Statistics Service of Ukraine. (2019). Transit freight for the period 2008-2019 years. Retrieved from https://www.ukrstat.gov.ua

Teodorovic, D., \& Janic M. (2016). Transportation Systems. Transportation Engineering, 2, 5-62. doi:10.1016 / b978-0-12-803818-5.00002-0.

Wu, J., Guo, X., Sun, H., \& Wang, B. (2014). Topological effects and performance optimization in transportation continuous network design. Mathematical Problems in Engineering, 2, 51-68. doi:10.1155/2014/490483.

Zakharov, Yu, \& Karnauk, E. (2014). The main modern tools of simulation of traffic flows. Bulletin of Pridneprovsk State Academy of Civil Engineering and Architecture, 1 (190), 46-51. Retrieved from http://visnyk.pgasa.dp.ua/article/download/39889/36019.

Zou, Y., \& Zhu J. (2016). Reachability of higher-order logical control networks via matrix method. Applied Mathematics and Computation, 287, 50-59. doi:10.1016/j.amc.2016.04.013.

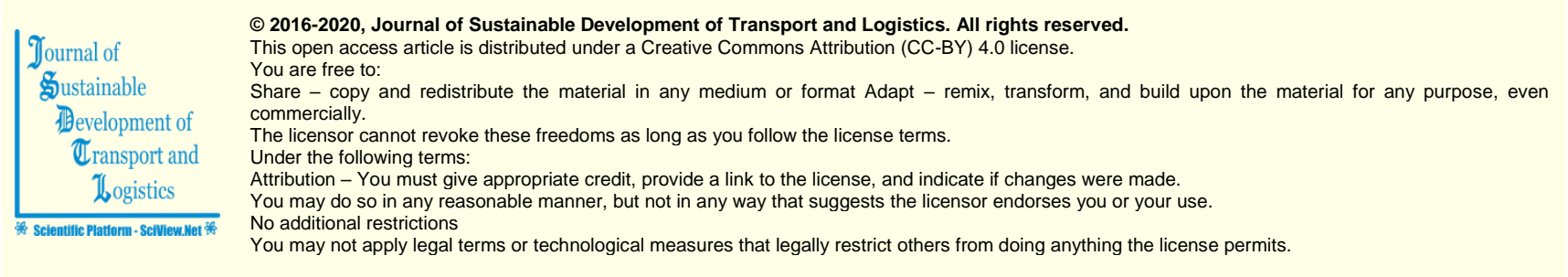

Journal of Sustainable Development of Transport and Logistics (ISSN: 2520-2979) is published by Scientific Publishing House "CSR", Poland, EU and Scientific Publishing House "SciView", Poland, EU

Publishing with JSDTL ensures:

- Immediate, universal access to your article on publication

- High visibility and discoverability via the JSDTL website

- Rapid publication

- Ruaranteed legacy preservation of your article

- Discounts and waivers for authors in developing regions

- Discounts and waivers for authors in developing regions 